\title{
AC 2009-139: THE PRACTICE OF CRITICAL THINKING AMONG ENGINEERING STUDENTS
}

\section{Elliot Douglas, University of Florida}

Elliot P. Douglas is Associate Professor of Materials Science and Engineering. His educational research interests include qualitative methods, critical thinking, and active learning in the engineering classroom. 


\title{
The Practice of Critical Thinking Among Engineering Students
}

\author{
Keywords: critical thinking, qualitative, constructivism
}

\begin{abstract}
Critical thinking is generally recognized as an important skill, and one that is a primary goal of higher education. Within engineering, although critical thinking does not appear on the required list of ABET outcomes many programs have adopted critical thinking as an ability which they wish to impart to their students. With the stated importance of critical thinking, it is vital to have a clear understanding of what critical thinking is. For the most part, conceptualizations of critical thinking have been approached from the philosophical perspective. That is, the definitions are not rooted in empirical studies, but rather in philosophical statements about what critical thinking is or ought to be. Most studies of critical thinking examine the critical thinking abilities of students using a quantitative instrument that operationalizes a particular conceptualization. What appears to be missing from the literature are empirical studies that examine the practice of critical thinking in order to understand the actual strategies used by students when they participate in what educators would consider to be critical thinking tasks. The lack of such an understanding makes it difficult to design effective interventions which will teach students how to realize the goal of being able to think critically. The purpose of this study is to examine how critical thinking actually occurs in practice. Semi-structured interviews were conducted with five civil engineering students at a large, public university. Students were shown problems from a standard critical thinking instrument and asked to solve them. The interviews involved asking the students about strategies they used in solving the problems, as well as questions relating to critical thinking in general. Thematic analysis of the interview transcripts identified five primary themes: reading comprehension, organizing information, using prior knowledge, using opinion, and making decisions. However, the ways in which these themes appeared varied considerably among the students. These results point to the variety of ways in which students can be expected to think critically. Understanding this variety is the first step towards developing interventions that address what experts might consider to be "poor" critical thinking and teaching students how to address engineering problems in a deeper, more critical way.
\end{abstract}

\section{Introduction}

Critical thinking is generally recognized as an important skill, and one that is a primary goal of higher education. As pointed out by Mason ${ }^{1}$ much of the rhetoric regarding education and its reform revolves around teaching students to think and question critically. Within engineering, although critical thinking does not appear on the required list of ABET outcomes many programs have adopted critical thinking as an ability which they wish to impart to their students.

With the stated importance of critical thinking, it is vital to have a clear understanding of what critical thinking is. For the most part, conceptualizations of critical thinking have been approached from the philosophical perspective. That is, the definitions are not rooted in empirical studies, but rather in philosophical statements about what critical thinking is or ought to be. Some of the most well known conceptualizations are those of Ennis, Paul, McPeck, and Martin (for a review, see reference ${ }^{1}$ ). An approach that comes closer to an empirical definition is 
that of Facione ${ }^{2}$ who convened an expert panel in a Delphi study to develop a definition of critical thinking. Even this approach, however, does not result in an understanding of critical thinking as it is practiced.

Most studies of critical thinking examine the critical thinking abilities of students using a quantitative instrument that operationalizes a particular conceptualization. While there have been numerous studies on the general college population (see for example the reviews in references ${ }^{3}$ and $\left.{ }^{4}\right)$ ), there are relatively few that specifically examine engineering students. ${ }^{5-8}$ In a previous study by the author, it was found that undergraduates actually outscored graduate students on the California Critical Thinking Skills Test, and that the difference was due to the graduates being unable to complete the instrument within the allotted time. ${ }^{9}$ A follow-up qualitative analysis suggested that the difference was due to different strategies used by undergraduate and graduate students when completing the instrument.

The literature review cited above shows that the existing studies on critical thinking assume certain conceptualizations of critical thinking and apply those definitions to interpret student behavior. There are very few empirical studies that examine the practice of critical thinking in order to understand the actual strategies used by students when they participate in what educators would consider to be critical thinking tasks. One exception is the Reflective Judgment Model of King and Kitchener. ${ }^{10}$ This model is based on qualitative studies, although it is now measured using a quantitative instrument, and has not been used for engineering students. Other examples exist for specific engineering tasks that require higher order thinking, such as examining the processes students use when confronted with a design task. ${ }^{11-13}$ The purpose of this study is to examine how critical thinking actually occurs in practice. It is driven by the following two research questions:

1. What are the processes students use to solve critical thinking problems?

2. What do students believe that critical thinking is?

These questions are examined within the context of the theoretical framework of Mason. As described above there are a number of conceptualizations of critical thinking, each of which emphasizes a different aspect. Mason ${ }^{1}$ has synthesized these different aspects into an overall conceptual framework. The components of his framework are (pp. 343-344):

- The skills of critical reasoning (such as the ability to assess reasons properly;

- A disposition, in the sense of:

- A critical attitude (skepticism [sic], the tendency to ask probing questions) and the commitment to give expression to this attitude, or

- A moral orientation which motivates critical thinking;

- Substantial knowledge of particular content, whether of:

- Concepts of critical thinking (such as necessary and sufficient conditions), or of

- A particular discipline, in which one is then capable of critical thought.

While most conceptions of critical thinking tend to focus on one or another of these components, Mason emphasizes an integrated approach which encompasses all of these aspects. 
An additional framework which informs this study is that of constructivism. Constructivist approaches to research focus on understanding how meaning is constructed by the individual. ${ }^{14}$ This qualitative study was approached from a constructivist perspective to identify the meaning that students make about critical thinking for themselves.

\section{Methods}

The participants in this study were undergraduate civil engineering students at a large public university. Participant characteristics are given in Table 1. Alice and Jose are older students. Alice is married with two young children. Jose is 33 years old, and served in the military before attending school. Interviews were conducted in which the students were shown four different problems taken from the California Critical Thinking Skills Test (CCTST), Form 2000. The first two problems were given exactly as on the CCTST. The second two problems were similar in nature to the first two, but they were given without the multiple choice answers. The exact questions can not be disclosed because of requirements imposed by the publisher on the use of the instrument. However, they can be described generally as non-engineering problems that are based on every day occurrences and do not require specialized knowledge. The questions were matched to be similar in type. Two of the questions (one with the answers provided and one without the answers provided) could be classified as "logic puzzles" that require, for example, placing items in an order based on certain requirements. The other two problems were ones in which a situation was presented and the students needed to come to some type of conclusion based on the evidence.

The interviews were semi-structured, with questions focused on the approaches the students used to solve the problems and general questions about how they have used critical thinking, both within and outside of engineering. The interviews lasted 40-60 minutes, and students were compensated \$20 for their participation. The interviews were recorded and transcribed verbatim.

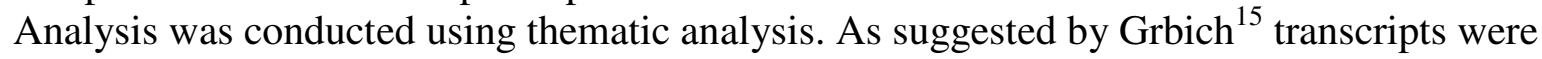
examined for statements that related to the research questions (p. 32). These statements were then grouped into themes through a constant comparative process.

Table 1: Participant characteristics.

\begin{tabular}{|l|l|l|l|l|}
\hline Name* & Sex & Race & Year of study & GPA \\
\hline Alice & female & white & junior & 3.69 \\
\hline Mike & male & white & junior & 3.36 \\
\hline Angela & female & Hispanic & junior & 3.82 \\
\hline Luis & male & Hispanic & senior & 3.02 \\
\hline Jose & male & Hispanic & senior & 3.20 \\
\hline
\end{tabular}

*Names are pseudonyms.

\section{Findings}

Five primary themes associated with critical thinking were identified from the interviews: identifying the problem and information, organizing information, using prior knowledge, using opinion, and making decisions. Each of these themes is discussed further below: 
identification: All of the students described the need to identify the purpose of the problem and the relevant information needed to solve the problem. This process took several forms, ranging from simply reading the problem statement to specifically targeting certain information. For example, in solving one of the problems Mike said "I'm just reading it....and then I had to read it over again...I'm just trying to process what I just read." Similarly, Alice stated that, "And as soon as I understood the direction that it was going I realized, OK, I need to read this very carefully, and so I reread it again, and then I understood now, even better, what I need to be looking for." Jose explicitly discussed the need to understand the purpose of the problem. "...first we have to see the purpose of the question. If it is to test what my prior knowledge is, or if it is to test my reasoning based on the question." In solving one problem, Luis noted that it was necessary to filter the information provided to come to an answer. "...it's just secondary data that you don't need..." Careful reading and understanding of the problems appeared to be the first step used towards solving them.

organizing information: Another general skill that was used by students was strategies for organizing the information presented in the problems. This organization was done in a variety of ways. Luis used both mental representations and visual representations of the information: “...just trying to picture things in your head and then how would you solve a problem...", “...this little diagram that I drew here...'cause that helps your visualize as well." Mike, in contrast, used only mental representations of the data: "I started drawing a linear relationship in my head." "I just went straight through trying to notice the different ratios." On one of the multiple choice questions, Alice provided a visual description of the mental process she used to select among the choices: "Even though I've thrown those out, they're [choices A and B] still kind of on the side","... when I finally make my decision then...I feel very sure about C...so now D is now in the margin for me", "They're [choices A and B] in the garbage."

using prior knowledge: Some students expressed that they did not look solely at the information in the problem, but also looked to prior knowledge that might help them. Jose felt that your level of prior knowledge affected how you might answer a question. "I know, because I have seen the word maybe a thousand times by now... But if we bring [in] someone that [does] not...know[s] anything about the problem, this would not be enough information." For Alice, the ability to use knowledge is a key component of critical thinking: "I had to really like, reach in and kind of pull out something that maybe wasn't right on the paper. And when you have to like go through your filing cabinet of stuff, then that would be a lot more critical." Mike saw critical thinking in everyday life as occurring "on the basis of everything that you've experienced and everything that shaped you to this point in your life."

using opinion: Although several students recognized that opinion could come into play when solving the problems, they used opinion in different ways. For Alice, her personal opinion was something to be wary of: "I mean, obviously these problems all deal with the most logical answers, so you have to separate your opinion from what you're trying to put on the paper." In contrast, Mike appeared to accept the use of his opinion as providing a means to get the answer: "This first one led me to the choice...because I thought that that was probably a cause of it." In discussing critical thinking in general, Mike placed a large emphasis on the role of opinion: "What's true to you and what's not true to you I think you think critically about those issues." "I guess you just think about what's true to you, what's ethical, what's right to you." 
making decisions: All students stated that their answers needed to be based on sound decisions that could be justified. Mike's approach to the problems was to "just reason it, make sure that what I've got down, my answer, makes sense to me." Even when the problem did not involve any complicated knowledge, according to Alice justifying the final answer was important: "It's not that hard of a problem, but I have to really think about the fact that I could have more than one answer... and that I have to come up with that on my own, and be able to stand behind it." Angela felt that making decisions is at the heart of critical thinking. When asked if people can function without doing critical thinking, she answered, "Yeah. But that's when people don't make good decisions." Jose emphasized that for him critical thinking is the development of a process that leads to a decision. "Now you're [making] a conclusion based on an analysis..." Similarly, Luis discussed the process of arriving at a conclusion, but in his case the emphasis was on choosing the path to arrive at that conclusion. "...your...goal is to get to one answer,...which route are you gonna take to get there?"

In addition to these themes, the students discussed what constitutes critical thinking. Here the conceptualizations varied widely. Alice believed that critical thinking required you to think in a new way. If you use a known algorithm to solve a problem, for her that is not critical thinking. Jose felt that critical thinking was the development of a process to solve a problem. Thus, even if you use an established algorithm, that is still critical thinking because you are using a process that had to be created. Luis had an intermediate view, stating that a "plug and chug" problem could contain critical thinking if you thought about what the answer means and did not simply accept the answer as given.

\section{Discussion}

Overall, this study provides insight into critical thinking as practiced by students through the use of critical thinking problems as a stimulus. The use of specific problems allowed the students to be made aware of strategies that they might not have been able to articulate in a general discussion. The primary themes developed from the interview data appear to be consistent with a view that critical thinking consists of a set of skills. Within the context of Mason's framework

for critical thinking we see in the data evidence of several of his components. ${ }^{1}$ Clearly both Mike and Alice show that they are using the "skills of critical reasoning". They also both exhibit a disposition towards critical thinking, both "a moral orientation which motivates critical thinking" and "a critical attitude and the commitment to give expression to this attitude." However, some of the aspects of critical thinking described by Mason do not appear in the data, most notably a lack of the use of "probing questions". There are several possible reasons that this element does not appear. Most likely, the nature of the questions and setting did not allow for this to be evident. The questions themselves were self-contained, so if a student was to ask a probing question they may not have verbalized and would have found the answer in the problem statement, or not at all. Additional work (using, for example, formal think-aloud protocols) would be needed to identify these metacognitive strategies. In addition, the complex interplay of the various components of critical thinking as seen in this study does not seem to be captured even by Mason's integrated conceptualization. Alice talks about thinking at different levels, and the very different types of thinking she does when confronted with engineering problems versus non-engineering problems. While Mason's conceptualization still tends to categorize critical 
thinking into discrete components, it appears that the actual practice of critical thinking involves a series of interactions and feedbacks among these components.

Despite the common themes identified for all students, there are some important differences among them. Alice used both visual and mental representations to organize information, while Mike used only mental representations. How this difference might affect critical thinking is unknown. Another difference is in the way they used their personal opinions and prior knowledge. For Alice, her opinion is something to be handled carefully, perhaps even set aside, while Mike relies heavily on his opinion and using additional information that is not part of the problem statement. This is evident in the way they each handled the same problem having to do with academic ability by income level. Alice came up with one possible answer, but then "I realized that that's an opinion and so I scrapped that and then I think about well, what led me to that." In contrast, Mike concluded that "maybe the low income [students] are not learning as much at home," even though the problem statement had no information about the home environment. More broadly, the different conceptualizations of what constitutes critical thinking illustrates the different expectations of these students. The differences among these students highlights the variety of critical thinking behavior that might be expected to occur across engineering.

\section{Conclusion}

This study has provided some insight into the strategies used by five engineering students when solving critical thinking problems, and how these students use critical thinking in engineering. Although common strategies were identified, there are important differences in the way these strategies are implemented. Although preliminary, these results point to the variety of ways in which students can be expected to think critically. The findings also provide a jumping off point to address a number of issues related to critical thinking. Among the questions to be asked in future work are: How is critical thinking in engineering different from critical thinking in other fields? Are there differences between different engineering disciplines? How does critical thinking change as students proceed through their engineering studies? How do students differ from experts? This last question is one that has been addressed from a number of perspectives (see for example the book How People Learn ${ }^{16}$ ), but the problems in this study were selfcontained, which limits the need of the students to address many of the issues identified by previous studies on experts. Future work will examine the behavior of experts, which will allow a comparison to be made. Overall, understanding how students approach critical thinking tasks is the first step towards developing interventions that address what experts might consider to be "poor" critical thinking and teaching students how to address engineering problems in a deeper, more critical way.

\section{Bibliography}

1. Mason, M. (2007). Critical thinking and learning. Educational Philosophy and Theory, 39(4), 339-349. 
2. Facione, P. A. (1990). Critical thinking: A statement of expert consensus for purposes of educational assessment and instruction. Research findings and recommendations. ERIC No. ED315423. Millbrae, CA: The California Academic Press.

3. McMillan, J. H. (1987). Enhancing college students' critical thinking: A review of studies. Research in Higher Education, 26(1), 3-29.

4. Pascarella, E. T., \& Terenzini, P. T. (1991). How college affects students. San Francisco: Jossey-Bass Publishers.

5. Polanco, R., Calderon, P., \& Delgado, F. (2001). Effects of a problem-based learning program on engineering students' academic achievements, skills development and attitudes in a mexican university. ERIC No. ED453234. Mexico.

6. Fleming, J., Garcia, N., \& Morning, C. (1995). The critical thinking skills of minority engineering students: An exploratory study. Journal of Negro Education, 64(4), 437-453.

7. Hager, P., Sleet, R., \& Kaye, M. (1994). The relation between critical thinking abilities and student study strategies. Higher Education Research and Development, 13(2), 179188.

8. Whitmire, E. (1996). Undergraduate students' development of critical thinking skills: An institutional and disciplinary analysis and comparison with academic library use and other measures. ERIC No. ED402819. Michigan: Michigan Univ., Ann Arbor. Center for the Study of Higher and Postsecondary Education.

9. Douglas, E. P. (2006). Critical thinking of engineering students: Undergraduate vs. Graduate students. Proceedings, American Society for Engineering Education Annual Conference.

10. King, P. M., \& Kitchener, K. S. (1994). Developing reflective judgment. San Francisco: Jossey-Bass.

11. Atman, C. J., Adams, R. S., Cardella, M. E., Turns, J., Mosborg, S., \& Saleem, J. (2007). Engineering design processes: A comparison of students and expert practitioners. Journal of Engineering Education, 96(4), 359-379.

12. Atman, C. J., Cardella, M. E., Turns, J., \& Adams, R. (2005). Comparing freshman and senior engineering design processes: An in-depth follow-up study. Design Studies, 26(4), 325-357.

13. Cardella, M. E., Atman, C. J., Turns, J., \& Adams, R. S. (2008). Students with differing design processes as freshmen: Case studies on change. International Journal of Engineering Education, 24(2), 246-259.

14. Crotty, M. (2003). The foundations of social research. Thousand Oaks, CA: Sage Publications.

15. Grbich, C. (2007). Qualitative data analysis: An introduction. Thousand Oaks, CA: Sage Publications.

16. National Research Council (1999). How people learn. Washington, DC: National Academy Press. 